\title{
An Empirical Analysis of the Impact of Exchange Rates on Stock Prices
}

\author{
Wenqi Wei \\ Tongji University, Shanghai, China \\ weiwenqi@tongji.edu.cn
}

\begin{abstract}
With the deepening of economic openness, the domestic capital market is increasingly linked to the foreign exchange market, and changes in the exchange rate of a country's currency are often accompanied by significant fluctuations in the level of stock prices. This paper selects the panel data of the stock prices of different listed companies and the exchange rate of RMB to SDR from the first quarter of 2017 to the fourth quarter of 2020 to conduct regression analysis and robustness test. The results show that there is a significant negative relationship between exchange rate (under the direct markup method) and stock prices. Compared with stocks with lower stock prices and B shares, stocks with higher stock prices and A shares are more affected by exchange rate changes. Therefore, China should be cautious in the process of promoting capital account opening and deregulation of exchange rate, strengthen the management of fluctuations in the foreign exchange and stock markets to prevent stock market bubbles, and promote the reform of the B-share market to improve the efficiency of corporate financing and make China's financial market more complete.
\end{abstract}

Keywords: Exchange Rates; Stock Prices; Robustness.

\section{Introduction}

As an important component of the financial market, the stock market has the main functions of providing a place for enterprises to raise funds and reallocate social capital. It is often considered as an economic "barometer". Stock price is one of the core variables of stock market, which is closely related to the economic development of a country. In general, stock prices are influenced by many factors such as interest rates, exchange rates, the company's own conditions, and the political situation of the country. Among them, the exchange rate attracts more attention because with the deepening of economic openness, the domestic capital market is increasingly linked to the foreign exchange market, and changes in the exchange rate of a country's currency are often accompanied by significant fluctuations in the level of stock prices. In the case of China, as shown in Figures 1 and 2, the rapid appreciation of the RMB and the sharp rise in stock prices after the "721" exchange rate reform in 2005 and the rapid depreciation of the RMB and the sharp fall in stock prices after the " 811 " exchange rate reform in 2015 are both illustrations of this phenomenon. In terms of foreign countries, Japan, for example, was forced to appreciate the yen significantly after the signing of the "Plaza Agreement" in the 1980s, which promoted a series of asset price bubbles, for example, in stock prices; and the bubble economy had great negative impact on Japan's economic development. In-depth investigation of the impact of exchange rate on stock prices to better clarify the relationship between the foreign exchange market and the stock market and the mechanism of action is necessary in preventing and resolving risks in the financial market and avoiding the emergence of a bubble economy.

In the following chapters, this paper will be structured as follows: chapter two summarizes the relevant literature of scholars on the study of the impact of exchange rate on stock prices; chapter three explains the sources of data and preprocessing methods; chapter four proposes the main theoretical model of this paper and gives the econometric estimation methods, possible problems of the methods and their solutions; chapter five gives the model empirical estimation and the results of endogeneity and robustness tests; and chapter six draws the main conclusions and puts forward advice in policy based on the previous analysis. 
Volume 15 (2021)

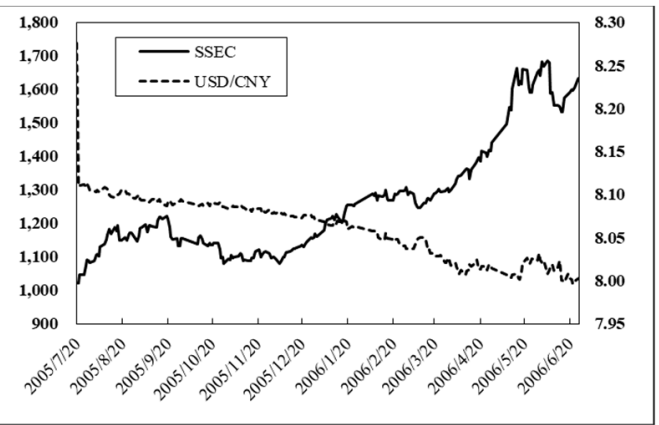

Figure 1. Changes in the USD/CNY exchange rate and SSEC index after the "721" exchange rate reform in 2005

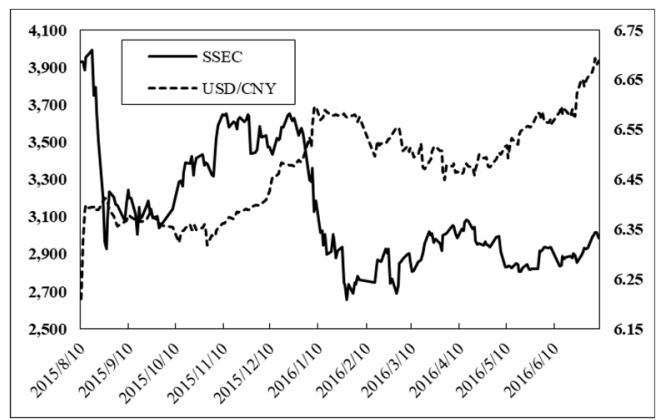

Figure 2. Changes in the USD/CNY exchange rate and SSEC index after the "811" exchange rate reform in 2015

\section{Literature Review}

Research on the impact of exchange rates on stock prices has been conducted since an early time, with earlier studies focusing on theoretical analysis. Dornbusch and Fischer (1980) proposed a floworiented model based on the product market hypothesis, which suggested that exchange rate changes affect stock prices by affecting the international competitiveness of export products. Branson (1983) proposed a stock-oriented model, which suggested that a country with an appreciating currency can attract more capital, improving its currency liquidity, and the excess liquidity will push up stock prices. Based on the stock-oriented model, Branson and Henderson (1985) proposed the theory of marketable securities balance based on the perspective of marketable securities holdings, argued that the propensity of security holders to increase their holdings of high-return assets and explained the inverse relationship between the exchange rate and stock price rewards by the direct markup method.

Based on the earlier theoretical analysis, some scholars have further explored this issue by building an empirical model. Deng Shen and Yang Chaojun (2008) used the daily data of the nominal exchange rate of RMB against USD and the SSE Composite Index under the direct markup method as samples, and found that there was a long-term stable co-integration relationship between the Chinese stock market and the exchange market after the "721" exchange rate reform in 2005, and the appreciation of RMB is the one-way Granger casuality. Zhu Xinrong and Zhu Zhenyuan (2008) used the GARCH model to conduct an empirical analysis and showed that the appreciation of the RMB had been driving the rise in stock prices from 2005 to 2007. Pu Siwei and Xu Chuangqiang (2012) concluded that an increase on the nominal effective exchange rate drives inflation and money supply, and the increased money tends to flow to the capital market, thereby pushing up stock prices. He Chengying et al. (2013) used the SV-TVP-SVAR model to conduct an empirical analysis and found that the relationship between the exchange rate and stock prices in China did not conform to either the flow-oriented model or the stock-oriented model when only the current period is considered. Wang Sheng and Zhao Chunchen (2020) used a DCC-GARCH model and found that the relationship is consistent with a flow-oriented model but not a stock-oriented model. 
Some scholars have also explored the heterogeneity of the impact of exchange rates on stock prices: (1) Currency heterogeneity: Ying Wu (2001) studied the impact of exchange rates between the Singapore dollar and the currencies of different countries on stock prices and found that the exchange rate of the Singapore dollar against the currencies of developed countries had a negative relationship with stock prices, while the exchange rate of the Singapore dollar against the Malaysian ringgit had a positive relationship with stock prices. Kou Mingting and Jing Haixia (2013) found that the exchange rate of RMB against USD showed a significant negative relationship with stock prices, while the exchange rate of RMB against AUD showed a significant positive relationship with stock prices. (2) Stock index heterogeneity: Sun Xianchao et al. (2017) found that, the SSE index and exchange rate (direct markup method) were positively correlated, while the SZSE index and exchange rate were negatively correlated. This may be due to the fact that most of the listed companies on the SSE are large and medium-sized state-owned enterprises, and most of them are exporters, which is consistent with the flow-oriented model. (3) Industry heterogeneity: Xiong Zhengde et al. (2013) studied the strategic emerging industries sector and found that the exchange rate had different effects on the stock prices of listed companies in different industries. (4) The heterogeneity of long-term and short-term effects: Zhao Hui and Shi Xianjin (2017) and Leng Song and Tian Gang (2017) used ECMT-GARCH and TVP-VAR-SV models respectively, and reached the same conclusion: RMB depreciation had a negative impact on stock prices in the short run, but also a positive impact on stock prices in the long run.

In addition, studies have also been conducted on the transmission mechanism of exchange rate and stock market effects: Dieci and Westerhoff (2013) used a general equilibrium approach and found that the relationship between exchange rate and stocks depended on the share of technical and fundamental traders in the market. Cheng, Haixing, Cheng, Si, and Zhu, Manzhou (2016) found that the impact of exchange rate shocks on the stock market strengthened as the internationalization of the RMB increased by conducting variance decomposition. Jayashankar and Rath (2017) found that for emerging countries like India, the link among the stock market, foreign exchange market, and currency market is more correlated, and negative or positive shocks affecting a market may be quickly transmitted to another market through contagion effects.

In summary, research on exchange rate and stock market issues has been carried out for a long time, but due to the different selection of indicators and periods, the conclusions obtained from the existing literature vary, and some scholars have further conducted heterogeneous studies and obtained richer results. Most of the existing studies used stock indices as indicators for stock price analysis, and the data structure is mostly time series data, and the exchange rate is mainly chosen from the local currency to another single currency, and there is little literature on the impact of the local currency to a basket of currencies on stock prices. The innovations of this paper are: (1) a panel data model with stock prices of different listed companies and the exchange rate of RMB against a basket of currencies in different periods is constructed; (2) two types of control variables at the firm level and macroeconomic level are added and (3) the impact of exchange rate on stock prices by combining the characteristics of China's financial market is analysed.

\section{Sources of Data and Preprocessing Methods}

\subsection{Main Indicators Selection and Data Sources}

For the explanatory variables, the StockPrice of listed companies on the Shanghai Stock Exchange and Shenzhen Stock Exchange from the first quarter of 2017 to the fourth quarter of 2020 are selected as indicators for analysis in this paper.

As for the core explanatory variables, one SDR unit equivalent to RMB (Yuan) is selected as the indicator of ExchangeRate for analysis because since the reform of exchange rate system announced on July 21, 2005 that China began to implement a managed floating exchange rate system based on market supply and demand, adjusted by reference to a basket of currencies, and the RMB exchange rate no longer pegged to a single US dollar, in order to more accurately reflect the real value of the 
RMB, China has continuously improved the reference mechanism of a basket of currencies and increased the reference to a basket of currencies. Therefore, in order to adapt to the trend of changes in China's exchange rate system, the exchange rate indicator of RMB against a basket of currencies can be selected for study when choosing the measure of exchange rate. As an international reserve asset created by the IMF, the composition and share of the currency basket of SDRs have internationally recognized determination criteria and measurement basis, and their value has strong credibility. Therefore, choosing one SDR unit equivalent to RMB (Yuan) as an exchange rate indicator can help to accurately describe the real level of RMB exchange rate.

The control variables in this paper contain two categories of firm-level control variables measuring individual firm differences and macroeconomic-level control variables measuring the performance of national economic fundamentals. The firm-level control variables include net assets per share (NAVPerShare), operating cash flow per share (OperatingNCFPerShare), cash dividends per share (DividentPerShare), and stock growth score (OGS), while the macroeconomic-level control variables include local currency interest rate (LocalRate), foreign currency interest rate (ForeignRate), GDP, central bank domestic credit balance (Credit), and tax revenue (Tax).

Among the above indicators, exchange rate and domestic credit balance data are obtained from the official website of the People's Bank of China, tax revenue data are obtained from the official website of the State Administration of Taxation, and the data sources of the remaining indicators are all from Guotaian CSMAR database.

\subsection{Data Preprocessing}

Among the above indicators, data such as stock price and exchange rate are daily or monthly data, while data such as GDP are quarterly data. In order to obtain a uniform frequency data panel, this paper achieves frequency reduction of high frequency data by averaging daily or monthly data by quarter, and unifies all data frequencies to quarterly frequencies. In addition, some of the observations have missing firm-level control variables, and these observations are excluded. The number of observations after pre-processing is 23,248 and the number of enterprises is 1,453 , including 16 periods from the first quarter of 2017 to the fourth quarter of 2020. The number of enterprises after processing accounts for about 70\% compared with that before processing, and the data are representative and can be used for subsequent analysis.

\subsection{Descriptive Statistics}

Table 1. Descriptive statistics results

\begin{tabular}{|c|c|c|c|c|c|c|}
\hline Variable & Explain & Obs & Mean & Std. Dev. & Min & Max \\
\hline StockPrice & Stock price & 23,248 & 15.4564 & 30.35227 & 0.2250615 & 1753.429 \\
\hline ExchangeRate & Exchange rate & 23,248 & 9.475185 & 0.1743981 & 9.1641 & 9.7276 \\
\hline NAVPerShare & Net asset per share & 23,248 & 6.011529 & 4.598617 & 0.546471 & 112.9411 \\
\hline $\begin{array}{c}\text { OperatingNCFPerShare } \\
\text { DividentPer } \\
\text { Share }\end{array}$ & $\begin{array}{c}\text { Operating cash flow per } \\
\text { share }\end{array}$ & 23,248 & 0.6376668 & 2.888434 & -109.8076 & 96.17977 \\
\hline OGS & Cash dividend per share & 23,248 & 0.1898997 & 0.3566913 & 0 & 14.539 \\
\hline LocalRate & $\begin{array}{c}\text { Local currency interest } \\
\text { rate }\end{array}$ & 23,248 & 2.461792 & 0.2445036 & 1.916015 & 2.777394 \\
\hline ForeignRate & $\begin{array}{c}\text { Foreign currency } \\
\text { interest rate }\end{array}$ & 23,248 & 1.283164 & 0.8881019 & 0.2447593 & 2.425502 \\
\hline GDP & Gross domestic product & 23,248 & 232994.7 & 29884.75 & 180682.7 & 293199.0 \\
\hline Credit & $\begin{array}{c}\text { Central bank domestic } \\
\text { credit balance }\end{array}$ & 23,248 & 124156.5 & 10311.84 & 107123 & 148260.2 \\
\hline Tax & Tax revenue & 23,248 & 34892.31 & 6202.985 & 25631 & 47164 \\
\hline
\end{tabular}


The results of descriptive statistics for each variable are shown in Table 1. Among them, the mean value of stock price is 15.46 and the standard deviation is 30.35 , indicating a large variation of stock prices among different companies; the mean value of exchange rate is 9.48 and the standard deviation is 0.17 , indicating a small fluctuation of exchange rate under the managed floating exchange rate system in China. In addition, Table 1 reports descriptive statistics for the remaining control variables.

\subsection{Covariance Test}

To test whether there is a multicollinearity problem among the variables, the correlation coefficients between the variables and the variance inflation factor (VIF) of the model are calculated, and the results are reported in Tables 2 and 3 respectively. The results of the correlation coefficient matrix show that the correlation coefficients between most of the variables are below 0.1 , and only the coefficients between stock price and net assets per share and stock price and cash dividends per share are slightly higher $(0.58,0.76)$, and there is no high correlation. The results of variance inflation factor calculation show that the maximum value of variance inflation factor for each variable is 2.95 and the mean value is 1.82 , none of which exceeds the empirical value of 10 . The combined results of the above analysis show that there is no serious problem of multicollinearity among the variables.

Table 2. Correlation coefficient matrix

\begin{tabular}{|c|c|c|c|c|c|c|c|c|c|c|c|}
\hline & $\begin{array}{l}\text { Stock } \\
\text { Price }\end{array}$ & $\begin{array}{l}\text { Exchange } \\
\text { Rate }\end{array}$ & $\begin{array}{c}\text { NAVPer } \\
\text { Share }\end{array}$ & $\begin{array}{c}\text { Operating } \\
\text { NCF } \\
\text { PerShare }\end{array}$ & $\begin{array}{l}\text { Divident } \\
\text { PerShare }\end{array}$ & OGS & $\begin{array}{l}\text { Local } \\
\text { Rate }\end{array}$ & $\begin{array}{l}\text { Foreign } \\
\text { Rate }\end{array}$ & GDP & Credit & Tax \\
\hline StockPrice & 1 & & & & & & & & & & \\
\hline ExchangeRate & -0.0217 & 1 & & & & & & & & & \\
\hline NAVPerShare & 0.5765 & 0.0263 & 1 & & & & & & & & \\
\hline $\begin{array}{c}\text { OperatingNCFPer } \\
\text { Share }\end{array}$ & 0.2732 & 0.0147 & 0.2536 & 1 & & & & & & & \\
\hline DividentPerShare & 0.7553 & 0.0262 & 0.6053 & 0.2858 & 1 & & & & & & \\
\hline OGS & 0.0047 & -0.0007 & 0.0696 & 0.0436 & 0.0004 & 1 & & & & & \\
\hline LocalRate & 0.0213 & -0.341 & -0.0247 & -0.002 & -0.0205 & 0.0006 & 1 & & & & \\
\hline ForeignRate & -0.0716 & 0.2145 & 0.0081 & -0.0286 & 0.0067 & 0.0003 & -0.1697 & 1 & & & \\
\hline GDP & -0.0172 & 0.5578 & 0.0294 & 0.0021 & 0.0262 & -0.0006 & -0.1687 & 0.0421 & 1 & & \\
\hline Credit & -0.0122 & 0.4778 & 0.04 & 0.0049 & 0.0274 & -0.0011 & -0.2425 & 0.053 & 0.775 & 1 & \\
\hline Tax & 0.008 & -0.1534 & 0.019 & 0.0031 & 0.0137 & -0.0005 & -0.5745 & -0.1442 & -0.1273 & 0.0203 & 1 \\
\hline
\end{tabular}

Table 3. Variance inflation factors

\begin{tabular}{|c|c|c|}
\hline Variable & VIF & $1 /$ VIF \\
\hline GDP & 2.95 & 0.339338 \\
\hline Credit & 2.64 & 0.379499 \\
\hline LocalRate & 2.22 & 0.450414 \\
\hline Tax & 2.05 & 0.48682 \\
\hline ExchangeRate & 1.89 & 0.530171 \\
\hline DividentPerShare & 1.63 & 0.612664 \\
\hline NAVPerShare & 1.61 & 0.621508 \\
\hline ForeignRate & 1.15 & 0.870478 \\
\hline OperatingNCFPerShare & 1.1 & 0.905428 \\
\hline OGS & 1.01 & 0.991055 \\
\hline Mean VIF & 1.82 & \\
\hline
\end{tabular}

\section{Theoretical and Empirical Models}

\subsection{Theoretical Model}

Based on the findings of Hema and Jaffee (1971), Modigliani (1972) and others on the influence of money on stock prices, Hamburger and Kochin (1972) further explored the channels of stock price influence and proposed a model of stock price determination applicable to mature financial markets. 
Volume 15 (2021)

$$
S P=S P(Y, P, r)
$$

Here SP is the stock price, $\mathrm{Y}$ is the GDP, $\mathrm{P}$ is the price level, and $\mathrm{r}$ is the interest rate level.

However, equation (1) is proposed for mature financial markets and cannot be directly applied to China's current stock market. This is due to the short history of China's stock market development, there is still much immaturity. One of the important performance is that compared with the mature stock markets in Europe and the United States, China's stock market turnover rate is high, most of them exceed the extreme value of $200 \%$. High turnover rate is an indication of the strong speculative motives of investors in China's stock market. According to Keynes' theory of money demand, people's money demand sources include three major motives: transaction motive, prevention motive, and speculation motive. When the money supply exceeds people's demand for trading and prevention motives, the speculation motive will drive people to put money into the market to make arbitrage. With the emergence of China's stock market, investors are increasingly interested in stock investment, and buying stocks has become a major choice for people to speculate, and the influx of excess money into the stock market will drive stock prices up. It can be seen that the high speculative motive of China's stock market is related to the money supply, and the money supply will become an important factor affecting the price of China's stock market. Thus, based on the actual situation of China's stock market, equation (1) is modified by introducing the money supply (M).

$$
S P=S P(Y, P, r, M)
$$

The formula for determining the money supply is:

$$
M=K \times B
$$

Here $\mathrm{K}$ is the money multiplier and $\mathrm{B}$ is the base currency.

Factors influencing base money include exchange rate (e), foreign exchange reserves (U), central bank domestic credit balance (W) and other factors (X):

$$
B=B(e, U, W, X)
$$

The combination of (4) and (3) leads to:

$$
M=K \times B(e, U, W, X)
$$

Among them, the mechanism of the exchange rate's influence on the money supply is that, under a government-managed exchange rate system, when the local currency faces greater appreciation pressure, the government will choose to sell the local currency and buy foreign currency to prevent a sharp shock in the foreign exchange market, increasing the country's foreign exchange reserves and making the money supply of the local currency increase; similarly, it can be seen that when the local currency faces greater depreciation pressure, the government will sell foreign currency and buy the local currency, making the money supply of the local currency decrease.

The combination of (5) and (2) leads to:

$$
S P=S P[Y, P, r, K \times B(e, U, W, X)]
$$

Here SP represents stock price, Y represents GDP, $\mathrm{P}$ represents price level, $\mathrm{r}$ represents interest rate level, $\mathrm{K}$ represents money multiplier, e represents exchange rate, $\mathrm{U}$ represents foreign exchange reserves, and $\mathrm{W}$ represents central bank domestic credit balance.

From the above theoretical model, it can be seen that the exchange rate will have an impact on stock prices: when the local currency is under pressure to appreciate, the government will increase 
the money supply in the local currency by buying foreign currency, and in the context of the existence of a high speculative motive in stock market, the extra money will enter the stock market to speculate and raise stock prices; conversely, when the local currency is facing depreciation, the money supply will decrease and the stock market will have less money, which will lead to lower stock prices .

\subsection{Empirical Model}

\subsubsection{Regression Equation and Interpretation of Variables}

Based on the above theoretical model, in order to further estimate the impact of exchange rate changes on stock prices, the benchmark econometric model used in this paper is as follows:

$$
\text { StockPrice }_{i t}=\lambda_{i}+\gamma_{t}+\beta_{1} \text { ExchangeRate }_{i t}+\sum_{k=2}^{K} \beta_{k} X_{k i t}+u_{i t}
$$

Here StockPrice is the explanatory variable stock price, $\lambda_{i}$ and $\gamma_{t}$ are individual fixed effects and time fixed effects, respectively, ExchangeRate ${ }_{i t}$ is the core explanatory variable exchange rate, which is expressed in RMB in one SDR unit in this paper, and, $X_{k i t}$ is the control variable, including firm-level control variables: net assets per share (NAVPerShare), operating cash flow per share (OperatingNCFPerShare), cash dividends per share (DividentPerShare), and Stock Growth Score (OGS), as well as macroeconomic-level control variables: local currency interest rate (LocalRate), foreign currency interest rate (ForeignRate), gross domestic product (GDP), central bank domestic credit balance (Credit), and tax revenue (Tax).

The above control variables were chosen for following reasons.

(1) Firm level control variables.

1) Net asset per share measures the present value of assets per share, the higher the net asset per share, the stronger the asset support per share of the company, the stronger the protection against risk, and the stronger the willingness of investors to buy this stock, which will push up the stock price. 2) Operating cash flow per share measures the ratio of net cash flow from operating activities to total equity, and companies with better cash flow have stronger liquidity and greater potential for future development, which will help stock prices rise. 3) Cash dividends per share measures the amount of dividends per share brought to stockholders, and stocks with higher levels of cash dividends have a stronger ability to attract long-term investors. 4) Stock growth score is calculated as follows: Stock growth score $=$ earnings growth rate $* 25 \%+$ net asset growth rate $* 25 \%+$ net asset growth rate $*$ $25 \%+$ stock price. $25 \%+$ net asset growth rate $* 25 \%+$ main business income growth rate* $25 \%+$ operating cash flow growth rate*25\%. Stock growth score can reflect whether the company's future development prospect is bright or not, and stock growth score has a positive impact on stock price.

(2) Macroeconomic level control variables.

1) Interest rate is an important influencing factor for stock prices, but its functional direction is more complex. Intuitively, for one thing, lower local currency interest rates will cause residents to save less and invest more in the stock market, which will lower the cost of corporate financing and facilitate the development of corporate financing, which will help raise stock prices. For another, lower local currency interest rates signal lower investment returns in the home country, which will stimulate foreign investors to withdraw from the market and pull down stock prices. In addition, a decrease in local currency interest rates may be seen by investors as a sign of economic depression, and they may choose to withdraw their capital from the stock market in anticipation of unpromising future economic development, leading to a decline in stock prices. The analysis of the impact of foreign currency interest rates on stock prices is along the same lines as that of local currency interest rates, but in the opposite direction. Thus, the direction of the impact of interest rates on stock prices is more complex and needs to be further verified through actual data. 2) an increase in GDP leads to an increase in the demand for money in the real economy, which in turn leads to a weakening of excess liquidity, a decrease in the amount of money flooding the stock market due to excess liquidity, 
and a decrease in stock prices. 3) the increase in the central bank's domestic credit balance reduces the balance of money that the central bank can place, and the future money supply may be lower without a large increase in money issuance. In addition, interest rates are similar and the large amount of loans issued by the central bank may be seen as a pessimistic signal of economic performance, leading to the withdrawal of funds from the stock market and pulling down the level of stock prices.4) Higher tax revenues indicate a heavier tax burden on businesses and individuals, discouraging business operations and personal investment and lowering stock prices.

\subsubsection{The Basis of Estimation Strategy Selection}

This paper chose to use a fixed-effects model for regression for two specific reasons. First, intuitively, the data of companies used in this paper cover A and B shares in Shanghai and Shenzhen, representing almost the whole research sample, and the heterogeneity index can be considered constant within this sample interval. The random effect model requires that the explanatory variables are not correlated with the individual effects, and the individual effects are relegated to the random disturbance term, while the fixed effect model is chosen without meeting this requirement. Second, from the Hausman test results, the original hypothesis of no individual heterogeneity should be rejected at the $1 \%$ significance level, and the fixed effect model should be chosen.

Table 4. Hausman test results

\begin{tabular}{|c|c|c|c|c|}
\hline \multicolumn{5}{|c|}{---- Coefficients ---- } \\
\hline & (b) & (B) & (b-B) & $\operatorname{sqrt}\left(\operatorname{diag}\left(\mathrm{V} \_b-V \_B\right)\right)$ \\
\hline & fe & re & Difference & S.E. \\
\hline ExchangeRate & -1.47153 & -1.449295 & -0.0222358 & 0.0141155 \\
\hline NAVPerShare & 3.23989 & 2.808442 & 0.4314476 & 0.0321378 \\
\hline OperatingNCFPerShare & 0.1525037 & 0.1758756 & -0.0233719 & 0.0037873 \\
\hline DividentPerShare & 32.4837 & 35.21297 & -2.729271 & 0.1699661 \\
\hline OGS & 0.0882782 & -0.0084375 & 0.0967157 & 0.0297392 \\
\hline LocalRate & 1.110069 & 1.115918 & -0.0058485 & 0.0012784 \\
\hline ForeignRate & -2.566591 & -2.551367 & -0.0152234 & 0.0014937 \\
\hline GDP & -0.0000246 & -0.000025 & $3.30 \mathrm{E}-07$ & 5.22E-08 \\
\hline Credit & -0.0000377 & -0.0000329 & $-4.86 \mathrm{E}-06$ & $5.50 \mathrm{E}-07$ \\
\hline Tax & -0.0000796 & -0.0000761 & $-3.52 \mathrm{E}-06$ & $5.48 \mathrm{E}-07$ \\
\hline _cons & 17.21904 & 18.60833 & -1.389295 & . \\
\hline \multicolumn{5}{|c|}{$\mathrm{b}=$ consistent under Ho and Ha; obtained from $\mathrm{xtreg}$} \\
\hline \multicolumn{5}{|c|}{$\mathrm{B}=$ inconsistent under Ha, efficient under Ho; obtained from xtreg } \\
\hline \multicolumn{5}{|c|}{ Test: Ho: difference in coefficients not systematic } \\
\hline \multicolumn{5}{|c|}{$\operatorname{chi} 2(5)=(b-B){ }^{\prime}\left[\left(\mathrm{V} \_b-V \_B\right)^{\wedge}(-1)\right](b-B)$} \\
\hline \multicolumn{5}{|c|}{$=400.39$} \\
\hline \multicolumn{5}{|c|}{ Prob $>$ chi $2=0.0000$} \\
\hline \multicolumn{5}{|c|}{ (V_b-V_B is not positive definite) } \\
\hline
\end{tabular}

\section{Empirical Results}

\subsection{Analysis of Baseline Regression Results}

The core explanatory variables exchange rate, firm-level control variables, interest rate variables in macroeconomic-level control variables and other macroeconomic-level control variables are introduced in turn, and the results of the benchmark regression are shown in Table 5. From the results, it can be seen that for the core explanatory variables, there is a significant negative relationship between exchange rate (under the direct markup method) and stock prices at the $5 \%$ significance level, indicating that appreciation of the local currency significantly drives up the stock prices of the home 
country; for the firm-level control variables, net assets per share, operating cash flow per share, cash dividends per share, and stock growth score are positively related to stock prices and are significant at the $1 \%$. For macroeconomic level control variables, local currency interest rates are positively correlated with stock prices, while foreign currency interest rates, gross domestic product, central bank domestic credit balance, and tax revenue are negatively correlated with stock prices, and all variables have high significance. Combined with the analysis of control variables in Part IV, it can be concluded that macroeconomic variables have a greater impact on the psychological expectations of investors in China's stock market. Taking the local currency interest rate as an example, from the theoretical analysis, it can be concluded that there are two ways to influence stock prices by lowering the interest rate: one is that it may make investors make pessimistic expectations about the economy, pulling funds out of the stock market and pulling down stock prices; the other is that it may reduce residents' willingness to save and stimulate them to The second is that it may reduce residents' willingness to save and stimulate them to invest more funds in the stock market, pulling up stock prices. The combined regression results show that lower interest rates have a greater effect on pulling down stock prices. This result is also consistent with the findings of Chen Hao (2014).

Table 5. Baseline regression results

\begin{tabular}{|c|c|c|c|c|}
\hline & (1) & $(2)$ & (3) & (4) \\
\hline & StockPrice & StockPrice & StockPrice & StockPrice \\
\hline \multirow[t]{2}{*}{ ExchangeRate } & $-3.785 * * *$ & $-7.717 * * *$ & $-3.879 * * *$ & $-1.472 * *$ \\
\hline & $(-7.23)$ & $(-17.49)$ & $(-8.33)$ & $(-2.50)$ \\
\hline \multicolumn{2}{|c|}{ NAVPerShare } & $3.123 * * *$ & $3.168 * * *$ & $3.240 * * *$ \\
\hline & & $(49.27)$ & $(50.88)$ & $(51.89)$ \\
\hline \multicolumn{2}{|c|}{ OperatingNCFPerShare } & $0.195 * * *$ & $0.158 * * *$ & $0.153 * * *$ \\
\hline & & $(6.02)$ & $(4.97)$ & $(4.80)$ \\
\hline \multicolumn{2}{|c|}{ DividentPerShare } & $32.35 * * *$ & $32.40 * * *$ & $32.48 * * *$ \\
\hline & & $(59.20)$ & $(60.43)$ & $(60.79)$ \\
\hline \multirow{2}{*}{ OGS } & & $0.0848 * * *$ & $0.0931 * * *$ & $0.0883 * * *$ \\
\hline & & $(2.76)$ & $(3.09)$ & $(2.94)$ \\
\hline \multirow[t]{2}{*}{ LocalRate } & & & $2.665 * * *$ & $1.110^{* *}$ \\
\hline & & & $(8.10)$ & $(2.43)$ \\
\hline \multicolumn{2}{|c|}{ ForeignRate } & & $2367 * * *$ & $2567 * * *$ \\
\hline & & & $(-27.17)$ & $(-28.41)$ \\
\hline \multirow{2}{*}{ GDP } & & & & $-00000246 * * *$ \\
\hline & & & & $(-5.73)$ \\
\hline & & & & \\
\hline \multirow[t]{2}{*}{ Credit } & & & & $-0.0000377 * * *$ \\
\hline & & & & $(-3.19)$ \\
\hline \multirow{2}{*}{ Tax } & & & & $-00000796 * * *$ \\
\hline & & & & $(-4.60)$ \\
\hline \multirow[t]{2}{*}{ cons } & $51.32 * * *$ & $63.33 * * *$ & $23.18 * * *$ & $17.22 * * *$ \\
\hline & $(10.35)$ & $(15.21)$ & $(4.92)$ & $(2.79)$ \\
\hline
\end{tabular}

Note: $* * *, * *$, and $*$ indicate the significance at $1 \%, 5 \%$, and $10 \%$ significance levels respectively, which will be presented in the same way in the following tables in this paper. 


\subsection{Analysis of Endogeneity Test Results}

In order to prevent the problem of endogeneity of the model due to mutual causality of the explanatory and explanatory variables and omission of explanatory variables, this paper uses the exchange rate with one period lag as the instrumental variable of the current exchange rate for endogeneity testing, and the results are shown in the following table. The estimated results of the instrumental variables method show that: 1 . there is still a negative correlation between the exchange rate and stock prices, indicating that the conclusion that the appreciation of the local currency can drive up the stock prices of the country still holds. 2 . The estimated coefficient of the exchange rate increases in absolute value and is more significant compared with the benchmark regression, indicating that the original model without considering endogeneity tends to underestimate the impact of the exchange rate on stock prices. 3 . The significance and sign of the control variables basically remain consistent.

Table 6. Endogeneity test results

\begin{tabular}{|c|c|c|}
\hline & $(1)$ & $(2)$ \\
\hline & Baseline regression & Instrumental variable method \\
\hline ExchangeRate & $-1.472^{* *}$ & $-5.147^{* * *}$ \\
\hline & $(-2.50)$ & $(-3.66)$ \\
\hline firm-level control variables & & Yes \\
\hline macroeconomic-level control variables & & \\
\hline & Yes & Yes \\
\hline & & \\
\hline cons & & $58.34 * * *$ \\
\hline
\end{tabular}

Note: Yes indicates that these variables are controlled, which will be presented in the same way in the following tables in this paper.

\subsection{Analysis of Robustness Test Results}

\subsubsection{Full-sample Robustness Test}

To test the robustness of the full sample, this paper runs a regression with the US dollar to RMB exchange rate replacing one SDR unit equivalent in RMB (Yuan) as a measure of the exchange rate under the direct markup method. The regression results reported in Table 7 show that the exchange rate remains negatively correlated with stock prices at the $10 \%$ significance level, i.e., the appreciation of the RMB increases stock prices, consistent with the findings above. The significance and sign of the control variables remain largely consistent. This shows the Full-sample robustness.

\subsubsection{Sub-sample Robustness Test}

This paper categorizes the samples according to the type of stock as A-share or B-share, the high or low price of the stock, and the industry to which the company belongs, and thus conducts Subsample robustness analysis.

\subsubsection{Samples Categorized by A-share Stocks and B-share Stocks}

The samples selected in this paper consists of A-share stocks (RMB common stocks) and B-share stocks (RMB special stocks). The two types of stocks use different currencies for subscription and trading, with A-share stocks using RMB subscription transactions and B-share stocks using foreign currency subscription transactions. This may lead to differences in the impact of RMB exchange rate changes on the share prices of the two types of stocks. Therefore, this paper tests the subsample robustness by dividing the stocks according to their types as A shares or B shares. The regression 
results are presented in the following table. The results show that, first, the exchange rate has a significant negative correlation with the prices of both types of stocks, and the regression results of the benchmark model are robust; second, the absolute value of the coefficient before the exchange rate of the B-share subsample is slightly smaller than that of the A-share subsample, and the significance is weaker, indicating that the exchange rate changes have a smaller degree of influence on the prices of B-share stocks. The possible reasons for this phenomenon are: firstly, B-shares are traded in foreign currencies, and when the local currency appreciates, national investors will consider converting their local currency into more foreign currency to buy more B-shares, but when they sell B-shares, they will face a decrease in the amount of local currency that they can convert their earnings into. Considering these two effects, investors' willingness to buy will not be enhanced by the appreciation of the local currency, and thus the price of B shares is weakly affected by the change in the value of the local currency; secondly, B shares are relatively inactive and less responsive to exchange rate changes.

Table 7. Full-sample robustness test results

\begin{tabular}{|c|c|c|c|c|}
\hline & (1) & (2) & (3) & (4) \\
\hline & StockPrice & StockPrice & StockPrice & StockPrice \\
\hline \multirow[t]{2}{*}{ USDExchangeRate } & $-2.983 * * *$ & $-5.277 * * *$ & $-1.096 * * *$ & $-0.789 *$ \\
\hline & $(-6.87)$ & $(-14.42)$ & $(-2.75)$ & $(-1.75)$ \\
\hline \multirow[t]{2}{*}{ NAVPerShare } & & $3.075 * * *$ & $3.143 * * *$ & $3.238 * * *$ \\
\hline & & $(48.50)$ & $(50.46)$ & $(51.87)$ \\
\hline \multirow[t]{2}{*}{ OperatingNCFPerShare } & & $0.196 * * *$ & $0.155 * * *$ & $0.152 * * *$ \\
\hline & & $(6.02)$ & $(4.86)$ & $(4.79)$ \\
\hline \multirow[t]{2}{*}{ DividentPerShare } & & $32.33 * * *$ & $32.32 * * *$ & $32.48 * * *$ \\
\hline & & $(59.01)$ & $(60.20)$ & $(60.77)$ \\
\hline \multirow{2}{*}{ OGS } & & $0.0895 * * *$ & $0.0961 * * *$ & $0.0886^{* * *}$ \\
\hline & & $(2.91)$ & $(3.18)$ & $(2.95)$ \\
\hline \multirow[t]{2}{*}{ LocalRate } & & & $3.188 * * *$ & $1.161^{* *}$ \\
\hline & & & $(9.51)$ & $(2.42)$ \\
\hline & & & & \\
\hline \multirow[t]{2}{*}{ ForeignRate } & & & $-2.435 * * *$ & $-2.568 * * *$ \\
\hline & & & $(-27.61)$ & $(-28.34)$ \\
\hline \multirow[t]{2}{*}{ GDP } & & & & $-0.0000264 * * *$ \\
\hline & & & & $(-6.30)$ \\
\hline & & & & \\
\hline \multirow[t]{2}{*}{ Credit } & & & & $-0.0000427 * * *$ \\
\hline & & & & $(-3.59)$ \\
\hline & & & & \\
\hline \multirow[t]{2}{*}{ Tax } & & & & $-0.0000767 * * *$ \\
\hline & & & & $(-4.35)$ \\
\hline \multirow{3}{*}{ cons } & & & & \\
\hline & $35.71 * * *$ & $26.33 * * *$ & $-7.173 * *$ & $9.440 * *$ \\
\hline & $(12.10)$ & $(10.56)$ & $(-2.31)$ & $(2.17)$ \\
\hline
\end{tabular}


Table 8. Regression results for the A-share and B-share Sub-samples

\begin{tabular}{|c|c|c|}
\hline & $(1)$ & $(2)$ \\
\hline & A-share stocks & B-share stocks \\
\hline ExchangeRate & $-5.078^{* * *}$ & $-4.521^{*}$ \\
\hline & $(-3.54)$ & $(-1.83)$ \\
\hline firm-level control variables & & Yes \\
\hline Yes & \\
\hline macroeconomic-level control variables & & Yes \\
\hline & Yes & \\
\hline cons & & $56.66^{* *}$ \\
\hline & $57.30^{* * *}$ & $(2.20)$ \\
\hline
\end{tabular}

\subsubsection{Samples Categorized by Stock Price}

From the previous descriptive statistics, it is clear that stock prices vary widely across companies. Considering that stocks with different stock prices may be affected by exchange rate changes to different degrees, the subsample robustness is tested by dividing the sample into high-priced stocks and low-priced stocks according to the $75 \%$ quantile of stock prices (17.48). The regression results are shown in Table 9. The results show that the exchange rate is negatively correlated with stock prices for both subsamples at the $10 \%$ significance level, indicating that the appreciation of the local currency drives up stock prices regardless of stock prices, and the findings are robust. Further comparison of the magnitude of the coefficients of the estimated values reveals that the absolute value of the coefficient is larger before the exchange rate of the subsample with higher stock prices, indicating that exchange rate changes have a greater impact on stocks with higher stock prices. The possible reason for this is that when the local currency appreciates it attracts foreign capital to the home stock market for speculation, and stocks with higher stock prices are more attractive to them, which makes such stocks more affected by exchange rate changes.

Table 9. Regression results for the stock price Sub-samples

\begin{tabular}{|c|c|c|}
\hline & $(1)$ & $(2)$ \\
\hline & Low Price Stocks & High Price Stocks \\
\hline ExchangeRate & $-1.947^{* * *}$ & $-9.238^{*}$ \\
\hline & $(-7.21)$ & $(-1.88)$ \\
\hline firm-level control variables & & Yes \\
\hline & Yes & Yes \\
\hline macroeconomic-level control variables & & \\
\hline & Yes & 82.32 \\
\hline & & $(1.52)$ \\
\hline
\end{tabular}

\subsubsection{Samples Categorized by the Company's Industry}

The data sample used in the benchmark regression of this paper contains listed companies from the whole industry, among which the real estate industry is characterized by a longer adjustment cycle and stricter intervention by policy control, and the financial industry has more mature experience in dealing with exchange rate fluctuations, so the degree to which stock prices in these two industries are affected by exchange rate changes may be different compared to other industries. Therefore, this 
paper divides the companies according to whether they belong to the financial or real estate industries to test the Sub-sample robustness. The regression results are shown in Table 10. The results show that although there is still a negative relationship between stock prices and exchange rates in the real estate and financial sectors, this negative relationship is not significant at the $10 \%$ level of significance. This shows that China's real estate industry may be relatively more affected by other factors such as economic cycles and policy regulation, while the financial industry is more resilient to exchange rate fluctuations, and the impact of exchange rate changes on these two industries is not significant.

Table 10. Regression results for the Sub-samples of the company's industry

\begin{tabular}{|c|c|c|c|}
\hline & $\mathbf{( 1 )}$ & $\mathbf{( 2 )}$ & $\mathbf{( 3 )}$ \\
\hline & Full sample & $\begin{array}{c}\text { Excluding the real estate sector } \\
\text { and the financial sector }\end{array}$ & $\begin{array}{c}\text { The real estate sector and the } \\
\text { financial sector }\end{array}$ \\
\hline ExchangeRate & $-5.147^{* * *}$ & $-5.967^{* * *}$ & -0.789 \\
\hline & $(-3.66)$ & $(-4.01)$ & $(-0.62)$ \\
\hline $\begin{array}{c}\text { firm-level control } \\
\text { variables }\end{array}$ & Yes & Yes & Yes \\
\hline & & & Yes \\
\hline $\begin{array}{c}\text { macroeconomic-level } \\
\text { control variables }\end{array}$ & Yes & & \\
\hline & & $65.64^{* * *}$ & \\
\hline & $58.34^{* * *}$ & $(4.22)$ & $21.93^{*}$ \\
\hline cons & $(3.97)$ & $1.66)$ \\
\hline
\end{tabular}

\section{Conclusion and Advice in Policy}

Summarizing the above empirical results, the following conclusions are drawn. First, the negative relationship between exchange rate and stock prices is significant, which means the appreciation of the local currency has a driving effect on the rise of stock prices in the home country; second, there is a significant negative relationship between exchange rate and stock prices of both $\mathrm{A}$ and $\mathrm{B}$ shares, but the B share stock prices are less affected by the change in exchange rate; third, the appreciation of the local currency significantly pushes up stock prices regardless of stock prices, but stocks with higher stock prices are pushed up to a greater extent; and fourth, the impact of exchange rate changes on stock prices in the real estate and financial sectors is not significant.

Based on the above findings, the following policy recommendations are proposed in conjunction with the current situation of China's financial market. (1) This paper finds that exchange rate changes have a significant impact on the stock market, and a significant appreciation of the local currency may drive a significant increase in stock prices, and a greater push for stocks with inherently high share prices. At present, China's financial market is still immature, once the capital flow and exchange rate floating liberalization is promoted too quickly, it is very easy to trigger the entire financial market turmoil due to the correlation of the foreign exchange market and stock market. Therefore, China should always uphold a prudent attitude in the process of promoting capital account opening and exchange rate deregulation, and should not be too hasty. The People's Bank of China and the China Securities Regulatory Commission should focus on the management of the correlation between the volatility of the foreign exchange and stock markets, strengthen cooperation in policy formulation and implementation, intervention and daily supervision, and promote marketization and the pursuit of economic efficiency while ensuring the stability of the financial market. (2) B-share stock prices are less affected by the exchange rate, which to a certain extent reflects the lack of liquidity and efficiency of the B-share market and the need for reform. The B-share market is a transitional market 
set up to attract foreign investment in China at the early stage of reform and opening up. With the establishment of FDI policy, QFII system and diversification of foreign investment channels, the status of B-share market is declining, and the shortcomings of poor financing ability and lack of liquidity are becoming increasingly apparent. As a transitional market, the reform of B-share market is inevitable. Carrying out reforms will help improve the efficiency of corporate financing and make China's financial market more complete and better adapted to the current situation of the times. The regulator should formulate reasonable reform guidance when conditions are suitable. Specific reform directions include B-share to A-share merger listing, buyback, merger and acquisition, etc. (3) Compared with mature stock markets, China's stock market speculation is serious, and investors rely excessively on subjective psychological expectations rather than rational judgment when making decisions. This leads to the overreaction of the stock market due to the large inflow and outflow of speculative funds and the blind obedience of investors when the foreign exchange market fluctuates, which is not conducive to the smooth operation of the financial market. Therefore, China should strengthen the management of the flow of speculative funds, especially foreign "hot money", and provide investors with the necessary education on basic investment knowledge to improve the overall quality of investors and guide them to make rational decisions.

\section{References}

[1] Branson W H, Henderson D W. Chapter 15 The specification and influence of asset markets [J]. Handbook of International Economics, 1985, 2:749-805.

[2] Branson W H. Macroeconomic Determinants of Real Exchange Risk in Managing Foreign Exchange Risk [J]. Cambridge University Press, Cambridge. 1983.

[3] Cheng Haixing, Cheng Si, Zhu Manzhou. Is the Exchange Rate an Important Factor in the Volatility of the Chinese Stock Market? [J]. Financial Forum (Wuhan), 2016(02):10-13.

[4] Chen Hao. An Empirical Study of the Impact of China's M2 and Inter-bank Lending Rates on the Stock Market [D]. Nanjing University, 2014.

[5] Deng Shen, Yang Chaojun. The Relationship between Chinese Stock Market and Exchange Market after Exchange Rate System Reform --An Empirical Study of Nominal RMB Exchange Rate and SSE Composite Index [J]. Journal of Financial Research, 2008(01):29-41.

[6] He Chengying, Liu Lin, Xu Xiangyang, Wang Zhanhai. Foreign Exchange Market Interventions, Exchange Rate Movements and Stock Price Volatility - A Theoretical Model and Empirical Study Based on Investor Heterogeneity [J]. Economic Research Journals,2013,48(10):29-42+97.

[7] Kou Mingting, Jing Haixia. A Study of Stock Price Effects of RMB Exchange Rate Fluctuations [J]. Business Times, 2013(28):49-51.

[8] Leng Song, Tian Gang. The Impact of RMB Exchange Rate and Interest Rate on Stock Market--Empirical Study Based on Time-Varying Parameter Vector Autoregressive model [J]. Journal of Finance and Economics, 2017(03):69-72+57.

[9] Liu Fangyao. Japan's Bubble Economy in the 1980s and the Lost Two Decades [D]. Shandong University of Finance and Economics, 2018.

[10] Malepati Jayashankar, Badri Narayan Rath. The dynamic linkage between exchange rate, stock price and interest rate in India [J]. Studies in Economics and Finance, 2017, 34(3).

[11] Michael J. Hamburger and Levis A. Kochin. Money and Stock Prices: The Channels of Influences [J]. The Journal of Finance, 1972 (2): 231-249.

[12] Roberto Dieci, Frank Westerhoff. On the inherent instability of international financial markets: natural nonlinear interactions between stock and foreign exchange markets [J]. Applied Mathematics and Computation, 2013, 221:306-328.

[13] Rudiger Dornbusch, Stanley Fischer. Exchange Rates and the Current Account [J]. American Economic Review, 1980, 70(5):960-971. 
[14] Sun Xianchao, Liu Xuehang, Li Jie. A Study on Relationship between Exchange Rate Volatility, QFII Investment and Chinese Stock Price --An Empirical Analysis Based on VAR model [J]. Price Theory and Practice,2017(03):124-127.

[15] Wang Sheng, Zhao Chunchen. The Transmission Mechanism Between RMB Exchange Rate and Stock Price--Empirical Test Based on DCC-GARCH Model [J]. Journal of Industrial and Technological Economics,2020,39(04):54-62.

[16] Wu Lihua, Fu Guangmin. The Interaction of RMB Exchange Rate, Short-term Capital and Stock Prices [J]. Economic Research, 2014, 49(11):72-86.

[17] Xiao Weiguo, Yuan Wei. Stock Market, RMB Exchange Rate and China's Currency Demand [J]. Journal of Financial Research, 2011(04):52-64.

[18] Xiong Zhengde, Wen Hui, Wan Jun. Exchange Rate and Stock Index Linkage: Empirical Study Based on Strategic Emerging Industry Sectors [J]. System Engineering, 2015, 33(07):73-79.

[19] Ying Wu. Exchange rates, stock prices, and money markets: evidence from Singapore [J]. Journal of Asian Economics, 2001, 12(3).

[20] Zhang Bin, Feng Sixian, Li Xindan, Wang Huijian. Exchange Rates and Stock Prices Interactions in China: An Empirical Studies after 2005 Exchange Rate Reform [J]. Economic Research Journal, 2008, 43 (09): $70-81+135$.

[21] Zhao Hui, Shi Xianjin. Study on the Impact of Exchange Rate, Interest Rate and Foreign Stock Price on Chinese Stock Price - An Empirical Study of ECM-T-Garch Based on High Frequency Data [J]. Financial Theory and Practice,2017(11):1-8.

[22] Zhu Xinrong, Zhu Zhenyuan. On the Correlation between RMB Exchange Volatility and Stock Price Returns [J]. Journal of Financial Research, 2008(11):99-107. 